\title{
Planejamento Estratégico na Indústria Imobiliária: Evidências de Mercado
}

\section{Oscar Fernando Osorio Balarine}

Doutor em Engenharia de Produção

Faculdade de Ciências Políticas e Econômicas-PUCRS

Av.Ipiranga, 6681 - 90619-900 Porto Alegre(RS)

balarine@music.pucrs.br

Palavras-Chave: Planejamento Estratégico, Desenvolvimento Imobiliário

Key Words:Strategic Planning. Property Development.

\section{RESUMO}

O artigo descreve aplicą̧̃es do planejamento estratégico à atividade imobiliária, levantando bibliografia existente e estratégias utilizadas por empresas incorporadoras no mundo real. Conclui-se que inúmeras empresas vem empregando consistentemente o planejamento estratégico em seus negócios, além de utilizarem criativas campanhas mercadológicas que contribuem para o sucesso dos empreendimentos.

\section{ABSTRACT}

This paper describes Strategic Planning improved to property development, and management strategies cases in brazilian real world. It is conclusive that many developers are using strategic planning and marketing to reach successful enterprises. 


\section{PRODUÇÃO}

\section{Introdução}

Experiências práticas, colhidas no mundo real das empresas, podem tornarse conhecimento útil que não só auxilie validar teorias mais amplas, mas também colaborar para a legitimação de funções específicas de subconjuntos da atividade empresarial.

Neste sentido, o objeto deste artigo é descrever a evolução do planejamento estratégico na indústria imobiliária, a partir da visão das organizações como sistemas interagindo com o ambiente social, de forma que políticas e ações sejam coordenadas e dirigidas para conjuntos comuns de metas (Porter, 1986).

Posteriormente, levantam-se casos práticos que mostram recentes caminhos percorridos por incorporadoras imobiliárias brasileiras no tratamento de seus mercados, a partir de visões estratégicas.

Para tanto, o método utilizado envolve pesquisa bibliográfica de teoria existente na área de planejamento estratégico, particularmente dirigida à atividade imobiliária, complementada por coleta de dados em processo de registro de performances.

Com este objetivo, o artigo está estruturado em quatro seções, iniciando por esta introdução, seguida de descrição teórica sucinta do planejamento estratégico na atividade imobiliária. Posteriormente, são descritas práticas observadas no mundo real, encerrandose o trabalho com comentários conclusivos.

\section{Planejamento Estratégico e Indústria Imobiliária}

A economia brasileira - e dentro dela o ambiente dos negócios imobiliários - tem se caracterizado pela descontinuidade, exigindo cuidado especial na formulação de estratégias. Num ambiente mutável, os participantes do mercado imobiliário necessitam agilidade e constante revisão de posicionamentos.

No entanto, se tal ambiente enseja oportunidades para negócios isolados, 0 esgotamento desses oportunismos pode representar sérios problemas àquelas empresas sem objetivos claramente definidos para atuação no médio e longo prazo. É preciso, pois, estabelecer uma visão nitida que guie a tomada de decisão e as ações complementares. Para tanto, a forma de elaborar abordagens especificas de mercado pressupõe realizar planejamento estratégico, cujo processo pode assumir os caminhos do fluxograma apresentado no Anexo A (Figura 1).

Nesse contexto amplo, Daniels \& Daniels (1996) indicam seis imperativos estratégicos como guia às atividades empresariais de longo prazo, identificados pelo:

a) estabelecimento de clara visão e aspirações da empresa, disseminando-as por toda a estrutura organizacional; 
b) identificação de clientes potenciais, suas necessidades e recursos;

c) estruturação das operações e gerenciamento de projetos locais, identificando relacionamentos mercadológicos e processos necessários à interação da empresa com o mercado;

d) cultivo de uma cultura de equipe, compartilhando informações e conhecimentos, em ambiente fértil e aberto;

e) identificação e desenvolvimento de alianças-chave de apoio ao esforço de conquista do mercado a atingir, com tais parceiros dispondo de competências e pontos fortes que complementem aqueles da empresa; e

f) utilização de tecnologia da informação como meio de domínio das atividades da empresa, mediante sistemas de apoio aos produtos, aos processos, ao conhecimento e à coordenação/controle dos sistemas.

De outro lado, Langford \& Male (1991) destacam a estratégia atingindo todos os niveis da organização, iniciando pela identificação de estratégias corporativas que tratam das decisões mais amplas, incluindo a escolha de objetivos gerais, aquisições e desinvestimentos. Para fomento das estratégias de negócios, aqueles autores indicam a necessidade de definir como a empresa poderá competir num mercado particular como, por exemplo, o mercado residencial de alta renda. A um terceiro nível são apontadas estratégias operacionais e de projetos, envolvendo decisðes tais como as definiçores de campos genéricos de competição.

Fischer (1986, pp.77-8) também mostra o sistema de planejamento corporativo atuando na formulação de planos em três niveis: (1) estratégias e planos corporativos, realizados ao nivel mais geral da organização; (2) estratégias e planejamento dos negócios, determinando o escopo das atividades, as áreas de operação e os objetivos a atingir com os projetos de produtos; e (3) estratégias e planos funcionais, que envolvem o planejamento ao nível mais baixo da organização, definindo desempenhos de pequenos grupos ou departamentos.

Este artigo enfocará o planejamento estratégico dentro de um modelo de competitividade (estratégias de negócios), buscando identificar quais decisões vem sendo adotadas pelas incorporadoras imobiliárias quanto à seleção dos produtos em que irão concorrer, a escolha dos mercados em que atuarão e com que recursos.

Assim, na seção seguinte, através da coleta de dados no mercado imobiliário, serão verificados quais campos de competição vem sendo eleitos pelas 
incorporadoras e que diferenciaçð̃es tem sido atingidas.

\section{Alternativas Estratégicas - Evidências de Mercado}

Segundo Contador (1995, p.43), ...acompanhar os movimentos dos concorrentes torna-se mais e mais importante à medida que cresce a disputa entre as empresas. Nesse contexto, a seguir são descritas evidências de mercado que mostram alternativas estratégicas adotadas por incorporadoras imobiliárias brasileiras, selecionadas mediante coleta de informações a partir de artigos publicados em periódicos. Tais informações estão classificadas por tipos de alternativas adotadas, que transcendem os campos analisados por Porter (1986), que identificou a concorrência empresarial através de estratégias amplas, centradas na Liderança de Custos e na Diferenciação. Abrindo esses campos estratégicos tradicionais, optou-se pela classificação em sete grupos, identificados como (1) Estratégias de Financiamento, (2) Recursos Mercadológicos, (3) Segmentação e Nichos de Mercado, (4) Internacionalização, (5) Parcerias, (6) Qualidade e Produtividade, e (7) Estratégias Dinâmicas.

\subsection{Estratégias de Financiamento}

O direcionamento do Sistema Financeiro Nacional ao mercado imobiliário tem enfrentado turbulências que remontam ao início do século.
Numa rápida revisão histórica identifica-se, até início dos anos 60 , tentativas isoladas do governo em montar estruturas de financiamento direcionadas à habitação (época dos Institutos de Aposentadoria, os $I A P E \hat{E S}$ ), cujos fracassos estão associados à ocorrência da inflação, inviabilizando aqueles sistemas de longo prazo.

Então em 21/08/64 é instituído o Sistema Financeiro Habitacional (SFH) e criado o Banco Nacional da Habitação (BNH), com a instituição do sistema de correção monetária e utilização de fontes de recursos baseadas em poupanças compulsórias (FGTS) e voluntárias (Cadernetas de Poupança). No entanto, inúmeras atitudes populistas adotadas inviabilizaram o sistema, em especial o descasamento do retorno dos investimentos (prestações), do reajustamento dos saldos devedores, culminando com o fechamento do BNH e transferência de seus ativos e passivos para a Caixa Econômica Federal (1986).

Como alternativa à indisponibilidade de financiamentos, no inicio dos anos 90 surgem os sistemas de autofinanciamento, cuja incompatibilidade associa-se à figura dos incorporadores assumindo função de agentes financeiros, papel que não lhes pertence.

Finalmente, em 1994 aparecem vários instrumentos de financiamento baseados em títulos mobiliários (securitização), que lentamente vão se solidificando e permitindo vislumbrar futuro promissor, 


\section{PRODUÇÃO}

com o SFH e a securitização atuando como sistemas simultâneos.

Nesse contexto, no início da década de 90 inúmeras incorporadoras de imóveis buscaram alavancar recursos para seus empreendimentos

oferecendo apartamentos a preços de pré-lançamento, $20 \%$ abaixo do preço de mercado (Gutierrez, 1992), ou até mesmo utilizando o recurso de permutar unidades com seus fornecedores de materiais e serviços, incluindo a própria aquisição do terreno, trocado por área construída (Benute, 1992).

Já em anos mais recentes vem amadurecendo importante mecanismo de revitalização do setor imobiliário, com a difusão do sistema de securitização (captação de recursos mediante emissão de valores mobiliários garantidos por recebiveis). Nessa linha, inúmeros titulos passam a compor o mercado financeiro imobiliário, destacando-se as debêntures imobiliárias (Balarine, 1990, p.80), cotas de fundos de investimento imobiliário (Lei

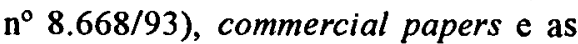
tradicionais, mas agora revigoradas, cédulas hipotecárias (Decretos-Leis $\mathbf{n}^{\circ} \mathbf{s}$. 70/66 e 1.494/76).

Com o advento da Resolução ${ }^{\circ} 2.122 /$ 94-BACEN, surgem então as Companhias Hipotecárias e Agências Securitizadoras, com o sistema funcionando em sequência onde $\left(1^{\circ}\right)$ as incorporadoras vendem seus recebiveis às Cias. Hipotecárias; $\left(2^{\circ}\right)$ as
Companhias Hipotecárias repassam os créditos às Agências Securitizadoras, recebendo os recursos a vista; $\left(3^{\circ}\right)$ as Agências Securitizadoras emitem titulos representativos dos créditos imobiliários, transformando-os em papéis negociáveis no mercado; $\left(4^{\circ}\right)$ os papéis emitidos são vendidos no mercado primário; e ${\left(5^{\circ}\right)}^{\circ}$ forma-se mercado secundário (Bolsas de Valores), garantindo liquidez aos títulos.

Assim, novos papéis surgem no mercado, desempenhando a função de transformar ativos imobiliários em financeiros. De outro lado, solidificamse os Fundos de Investimento Imobiliário, que agora buscam espaço definitivo através da participação em bolsas de valores, adicionando desejável liquidez a suas cotas. Com essas características, tais papéis vem suscitando interesse crescente por parte dos fundos de pensão, seguradoras e fundos mútuos, cujas reservas técnicas concentram o maior volume da poupança nacional.

Certamente, a securitização abre novo espaço para alianças entre incorporadores e grandes investidores institucionais, com tais mecanismos oferecendo alternativa estratégica importante, ao contribuirem para a geração de financiamentos destinados à produção. Além disso, permitem acomodar a capacidade de poupança dos compradores aos preços das unidades, sabidamente com enorme participação relativa em suas rendas (Balarine, 1996, p.131). 


\subsection{Recursos Mercadológicos}

A utilização de recursos mercadológicos inovativos vem colaborando para a expansão do mercado de incorporadoras que exploram singularidades típicas dos imóveis, através de campanhas criativas e diferenciadas.

Tais recursos são destacados particularmente na publicidade dos empreendimentos, fugindo aos padrões convencionais (foto da fachada, plantabaixa das unidades, etc.) como, por exemplo, a campanha realizada pela HCA Propaganda Ltda., mediante distribuição de sapinhos em origami nas sinaleiras de trânsito, contendo endereço de empreendimento com parque ecológico direcionado às crianças (Moraes, 1996).

Outra campanha publicitária criativa, associando o preço da casa própria a uma despesa singela, desmistifica o preço do imóvel ao comparar o desembolso diário com a compra da residência, ao preço de uma pizza, conforme campanha da MVR Engenharia Ltda. (Ribas, 1996).

Mas além de campanhas publicitárias, o mercado imobiliário busca explorar outros conceitos, como a flexibilidade dos projetos. Exemplo típico é identificado em empreendimento lançado pela CST Expansão U.rbana S.A., de Salvador (Rúbio, 1992), com os apartamentos (de três quartos) incluindo um dormitório reversivel em biblioteca ou sala de televisão.
Também na busca da flexibilização, o conceito vem sendo empregado no segmento de escritórios, como o executado pela Sulimob Empreendimentos Imobiliários Ltda., de São Paulo (Balarin, 1996), em lançamento que permite conjugar várias salas, além de contar com paredes divisórias removíveis, sem prejuizo às tubulações.

Aliás, na busca de diferenciar seus imóveis, os incorporadores agregam variados atrativos, como os 178 itens relacionados no Anexo B (Figura 2). Tal relação levanta a provável necessidade da indústria imobiliária rever seus modelos, já que potenciais compradores vem requisitando apartamentos com maior número de facilidades (máquinas de lavar, fornos de microondas, escritórios com redes de fibra ótica, etc.), além da exigência crescente por serviços nas centrais de portaria, envolvendo desde a compra de passagens aéreas, até a reserva de mesas em restaurantes.

\subsection{Segmentação e Nichos de Mercado}

A análise de segmentos de mercado é considerada básica para estratégias de marketing, na seleção de mercados-alvo e desenvolvimento de programas mercadológicos eficazes (Kotler, 1980). A palavra nicho, por sua vez, é definida como ...porção restrita de um hábitat onde vigem condiçzes especiais de ambiente (Ferreira, 1986, p.1192), identificando redutos a atingir mediante esforços de pesquisa que determinem 
interesses especificos, não inteiramente satisfeitos pelo mercado tradicional.

Por globalização entende-se uma nova ordem internacional, onde a dependência entre as nações presume o compartilhamento econômico e cultural, a divisão da produção em etapas realizáveis em países diversos e a queda de barreiras comerciais.

Dentro desse movimento global inserem-se, em escala mais reduzida, os blocos regionais de nações, onde países firmam alianças objetivando acelerar investimentos, com a formação de mercados mais abrangentes.

Toffler (1990, pp.259-61) esboça os elementos de um novo sistema de criação de riqueza tanto local como global, que ultrapassa a produção em massa, tornando a produção mais flexível, sob encomenda e baseada na troca do conhecimento.

Nesse novo espaço, esta pesquisa identificou empresas imobiliárias competitivas inserindo-se no atual movimento de mudança global, ultrapassando fronteiras nacionais $e$ atuando localizadamente em dois mercados geográficos, identificados pelo ambiente do Mercosul e pela região da Flórida (EUA).

No ambiente do Cone Sul, o crescimento dos negócios inclusive propiciou a criação do Grupo de Trabalho Permanente na Construção Civil e Engenharia do Mercosul-GTPCE
(Balarin, 1995), que se propõe a debater, posicionar o grupo e propor legislação que busque a homogeneização do mercado e obras.

Assim, multiplica-se a área de atuação de empresas como a Andrade Gutierrez, Benito Roggio, Birmann, CBPO, Edel e Rossi Residencial, que internacionalizaram suas operações tanto em obras públicas como realizando incorporações imobiliárias, centradas na opção estratégica de expandir suas atuações para um mercado global a partir dos países do Cone Sul.

Também na região da Flórida (EUA), as empresas brasileiras consolidam participação em obras públicas (Andrade Gutierrez, Odebrecht) e empreendimentos imobiliários (Edel, Multiplan) impulsionadas por financiamentos de longo prazo (30 anos) e juros baixos que podem assumir a forma fixa de $7,5 \%$ a.a. ou variável com taxa real de $5 \%$ a.a. (Balarin, 1996), ampliando progressivamente 0 espectro de investimentos no mercado norteamericano.

\subsection{Parcerias}

Drucker $(1995$, p.34) destaca a importante tendência atual para formação de alianças como veículo de crescimento empresarial, na forma de ...relações não baseadas em propriedade, mas em parceria: joint-ventures, investimentos minoritários consolidando acordos de marketing conjunto ou de pesquisa 


\section{PRODUÇÃO}

conjunta e alianças semiformais de todo o tipo.

Seguindo essa tendência, incorporadores e empreendedores brasileiros tem se associado, realizado fusões, adquirido outras empresas ou formado alianças estratégicas, visando oferecer soluções completas, diversificar clientes e ampliar seus campos de atuação.

$\mathrm{Na}$ área de crédito imobiliário, os gnupos Brasilinvest e Cobansa (Balarin, $12 / 03 / 96$ e 15/03/96) inovaram ao formar joint ventures e criar empresas direcionadas à prestação de serviços imobiliários conhecidos no exterior como Asset Management ${ }^{\text {}}$. Enquanto o grupo Brasilinvest uniu-se à empresa francesa Constructa para administrar ativos imobiliários, à Cobansa criou sua Companhia de Gestão Imobiliária como um braço da Cobansa Companhia Hipotecária, visando prestar serviços de administração de crédito imobiliário para bancos, construtoras, incorporadoras e compradores de imóveis.

Outro exemplo de parceria ampla reuniu a Construtora Tecnum, a DuPont, o Unibanco e a IBM, para incorporação de edifício residencial em São Paulo, numa aliança em que cada participante, em sua área específica, atua direcionado à realização do empreendimento (Biscaro, 23/07/96). Assim, a Tecnun constrói, a DuPont fornece impermeabilizantes e carpetes, o Unibanco administra o pagamento das unidades durante a construção, cabendo à IBM fornecer microcomputadores aos adquirentes da unidades, com acesso ao andamento das obras via Internet.

Também na região sul frutificam alianças, como a parceria formada pelas construtoras Pegoraro, Maiojama e Antahir Participações, objetivando construir o World Trade Center em Porto Alegre (Marchand, 28/08/96), composto de duas torres destinadas a hotel e espaços convencionais de negócios, centro de tecnologia de informações, centro de convenções, lojas de conveniências e restaurantes.

Certamente, quando a formação de joint ventures acresce capital e tecnologia, ou quando amplia e diversifica clientes, sempre será oportuno à empresa optar por essas alianças estratégicas, estabelecendo beneficios compartilhados.

\subsection{Qualidade e Produtividade}

Desde a década de 70 , as palavras qualidade e produtividade tem sido associadas ao movimento das empresas em busca de caminhos competitivos. Justo será, portanto, definir claramente o que elas representam, valendo-se dos conceitos econômicos registrados por Pass \& Lowes (1993), que definem (a) qualidade como ...o conjunto de atributos de um bem ou serviço que satisfazem os desejos de compradores ou consumidores (p.455); e (b) produtividade como ...a relação entre os bens ou serviços produzidos por uma unidade econômica 
e os fatores de produção utilizados para gerá-los (p.436). Conclui-se, pois, que o alcance de maior produtividade inclui obter melhor qualidade.

Estudos para aumento da produtividade vem recebendo dedicação contínua e proveitosa de instituições como o Programa de Qualidade e Produtividade na Construção Civil/RS - PQPCC/RS, que funciona junto ao Curso de PósGraduação em Engenharia Civil (CPGEC/NORIE) da Universidade Federal do Rio Grande do Sul-UFRGS, além da preocupação de incorporadores e construtores conscientes da importância em desenvolver metodologias que eliminem desperdícios e aumentem a qualidade das obras.

Neste sentido, avanço significativo está consolidado na definição de indicadores de produtividade e qualidade direcionados à medição de desempenho de empresas construtoras, levantados a partir de pesquisa realizada pelo CPGEC/ NORIE em parceria com empresas do setor, objeto de publicação intitulada Sistema de Indicadores de Qualidade e Produtividade da Construção Civil (Oliveira, Lantelme \& Formoso, 1993).

A existência de indicadores setoriais favorece às empresas não só acompanharem seu desempenho, como também beneficiarem-se desse acompanhamento pela oportunidade de utilizá-lo como benchmark2, avançando metas de melhoria contínua.

\subsection{Estratégias Dinâmicas}

Durante a pesquisa realizada visando alimentar este artigo com performances do mundo real, duas incorporadoras imobiliárias destacaram-se pelo registro de ampla e nítida estratégia mercadológica que, na ótica deste pesquisador, merecem tratamento diferenciado pela adoção de diversificadas opções estratégicas, muitas já descritas nos itens anteriores. Tais incorporadoras, Método Engenharia Ltda. e Cyrela Empreendimentos Imobiliários Ltda., ambas de São Paulo, demonstram criativa e contínua revisão de atuação no mercado, propiciando eleger suas políticas como estratégias dinâmicas.

a) Método Engenharia Ltda.: iniciando suas atividades nos primeiros anos da década de 70, esta incorporadora vem revisando consciente e sistematicamente suas estratégias maiores, solidificando destacada participação no mercado nacional.

A trajetória da empresa (Rosa, 1992) inicia em 1973 com a dedicação a obras por empreitada, caracterizada pelas dificuldades associadas à sazonalidade das obras e ao crônico atraso de pagamento das obras públicas. Num segundo momento - 1983/1986 - a estratégia passa a centrar-se na capitalização da empresa, informatização e profissionalização gerencial. Na terceira fase - 1987/1990 definem-se novos objetivos direcionados à produtividade e qualidade, buscando 


\section{PRODUÇÃO}

diferenciação; e agilidade e flexibilidade, numa adaptação a tempos de mudanças cada vez mais rápidas. Na década de 90 consolida-se a filosofia da empresa, com base em quatro principios (fazer bem feito, empresa como veículo social, relações trabalhistas democráticas e princípio da competência).

Como objetivos para o futuro, a empresa manifesta sua intenção em reestruturar-se organizacionalmente (redução de niveis hierárquicos), tornarse transparente através de comunicações mais abertas, concentrar maiores esforços no treinamento e dar ênfase total à área de produção, na busca de qualidade e produtividade. Nota-se, assim, a preocupação da empresa com um mercado competitivo, onde a escolha de tecnologia adequada e a definição de táticas maximizadoras da produção relacionamse intimamente com estratégias amplas, na busca do sucesso dos empreendimentos.

Mais recentemente, considerando as revisões estratégicas como marca de sua gestão, a Método revê seu posicionamento no mercado em face da maior agressividade de concorrentes estrangeiros e de novas perspectivas do setor (Trevisani Jr., 02/08/96). Atuando com quatro divisõ̃es (construção, telecomunicações, negócios imobiliários e banco interno), a empresa vem trabalhando com a expectativa de crescimento dos investimentos no mercado imobiliário, principalmente de fundos de pensão. b) Cyrela Empreendimentos Imobiliários Ltda.: esta incorporadora, com destacada participação em São Paulo, vem caracterizando sua atuação pelo uso de variados diferenciais qualitativos, antecipando-se às tendências de mercado.

Demonstrando criatividade invulgar no lançamento de seus empreendimentos, a Cyrela realiza madura aplicação do planejamento estratégico amparando o produto, baseada em parcerias e campanhas mercadológicas inovativas, como as descritas a seguir:

Inquilino Virtual: a empresa compromete-se a pagar aluguel mensal de $0,8 \%$ do valor da unidade para clientes que adquirirem suas unidades a vista, até que as obras sejam concluídas;

Fundo Imobiliário: a Cyrela constituiu um fundo imobiliário para construção de shoping temático (centro têxtil e de moda);

Flat de Escritórios: lançamento de edificio de escritórios, administrado nos mesmos moldes de um flat;

Joint Venture: associação com a empresa argentina Inversiones y Representaciones-Irsa, para lançamento de shoping center;

Edificio com Elevador para o Shabat: empreendimento dotado de elevador que satisfaz as exigências da religião judaica, que proibe realizar qualquer trabalho ou 


\section{PRODUÇÃO}

manipular qualquer equipamento durante o período do Shabat. Para tanto, o elevador é programado para parar automaticamente em cada um dos 38 pavimentos do edificio, durante as $\mathbf{2 4}$ horas do feriado religioso;

Fortalecimento de Marca: atuação constante em comunicação, ressaltando diferenciais qualitativos da marca Cyrela, caracterizada pela oferta de ampliações aos produtos, que excedem as espectativas normais dos clientes.

\section{Conclusões}

Este estudo procurou mostrar o ambiente estratégico em que se insere a atividade imobiliária no pais, partindo do levantamento de informações disponiveis na bibliografia e em artigos de periódicos.

Ao contrário do esperado, a pesquisa demonstrou que no Brasil muitas das empresas dedicadas à atividade de construção e incorporação imobiliária vem empregando consistentemente o planejamento estratégico em seus negócios. Mais do que isso, percebe-se agilidade nas definições, criativa utilização de campanhas mercadológicas e cuidado com o planejamento e controle de gestão.

Associando suas visões de longo prazo às táticas centradas no produto e no cliente, muitos incorporadores tem harmonizado seus recursos internos com as oportunidades de mercado.
Em país marcado pela descontinuidade das políticas econômicas, essa agilidade nas definições estratégicas tem se mostrado vital para o sucesso dos negócios dessas empresas que, com flexibilidade, conseguem atuar num setor identificado pela oferta de produto caro e direcionado a mercados restritos e exigentes.

\section{Notas}

1. Asset Management: atividade direcionada à administração de ativos imobiliários, assumindo no mercado financeiro o exercício da administração de portfolios formados por títulos imobiliários e recebiveis (Kyle \& Baird, 1991, p.443);

2. Benchmark: ponto de referência.

\section{Bibliografia}

BALARIN, R. Construção no Mercosul. Gazeta Mercantil, 05/04/95. p.8.

. Constructa Chega ao Brasil. Gazeta Mercantil, 12/03/96. p.C-2.

Miami Atrai Investidor Brasileiro. Gazeta Mercantil, 13/03/96. p.C-2.

. Parceria para o Crédito a Imóvel. Gazeta Mercantil, 15/03/96. p.B-3. 
Maior Flexibilidade nos Novos Escritórios. Gazeta Mercantil, 30/05/96, Caderno Propriedades. p.1.

BALARINE, O. Administração e Finanças para Construtores e Incorporadores. Porto Alegre, Edipuc, 1990. 196p.

. Determinação do Impacto de Fatores Sócio-Econômicos na Formação do Estoque Habitacional em Porto Alegre. Porto Alegre, Edipuc, 1996. 228p.

BENUTE, E. Encol Vai Construir Edifício para Negociá-lo com seus Fornecedores. Gazeta Mercantil, 02/12/ 92. p. 12 .

BISCARO, F. Tecnun Aposta em Projeto Conjunto no Morumbi. Gazeta Mercantil, 23/07/96, p.C-2.

CONTADOR, J. Recomendações sobre o Processo de Planejamento Estratégico. Revista de Administração de Empresas. São Paulo, V.35, N.3, pp.3948.

DANIELS, J. \& DANIELS, N. Visão Global: Criando Novos Modelos para as Empresas do Futuro. São Paulo, Makron Books, 1996. 233p.

DRUCKER, P. Administrando em Tempos de Grandes Mudanças. São Paulo, Pioneira, 1995. 230p.
FERREIRA, A. Novo Dicionário da Língua Portuguesa. Rio de Janeiro, Nova Fronteira, 1986. $2^{\mathrm{a}} \mathrm{Ed}$.

FISHER, N. Marketing for the Construction Industry. New York, Longman Inc, $1986.270 \mathrm{p}$.

GUTIERREZ, A. Vendas na Planta para Financiar Empreendimentos. Gazeta Mercantil, 26/02/92, p.8.

KOTLER, P. Marketing - Edição Compacta. São Paulo, Atlas, 1980. 589p.

KYLE, R. \& BAIRD, F. Property Management. Chicago, Dearborn, 1991. 4th.Ed. 469p.

LANGFORD, D. \& MALE, S. Strategic Management in Construction. Hants, Gower, 1991. 156 p.

MARCHAND, J. WTC do Sul Custará R\$ 200 Milhões. Gazeta Mercantil, 28/ 08/96. p.C-3.

MORAES, A. HCA Inova em Anúncios para o Setor Imobiliário. Gazeta Mercantil, 03/05/96, p. 9.

OLIVEIRA, M., LANTELME, E. \& FORMOSO, C. Sistema de Indicadores de Qualidade e Produtividade da Cosntrução Civil, Porto Alegre, CPGEC/NORIEUFRGS, 1993. 
PASS, C. \& LOWES, B. Dictionary of Economics. Glasgow, Harper Collins, 1993. 2nd.Ed. 569p.

PORTER, M. Estratégia Competitiva. Rio de Janeiro, Campus, 1986. 362p.

RIBAS, S. MVR Vende Imóveis a Preço de Pizza. Gazeta Mercantil, 26/06/ 96, p.16.

ROSA, H. A Método e sua Trajetória. Revista de Administração, USP, v.27, n.3, julho/setembro 1992. pp.107-17.

RÚBIO, P. Construtora Baiana Reduz pela Metade Área dos Apartamentos. Gazeta Mercantil, 24/03/92, p.5.

TOFFLER, A. Powershift: as Mudanças do Poder. Rio de Janeiro, Record, 1990. 613p.

TREVISANI JR., P. Método Faz da Mudança sua Rotina. Gazeta Mercantil, 02/08/96, p.C-2. 
Anexo A

Figura 1

Planejamento Estratégico - Fluxograma do Processo

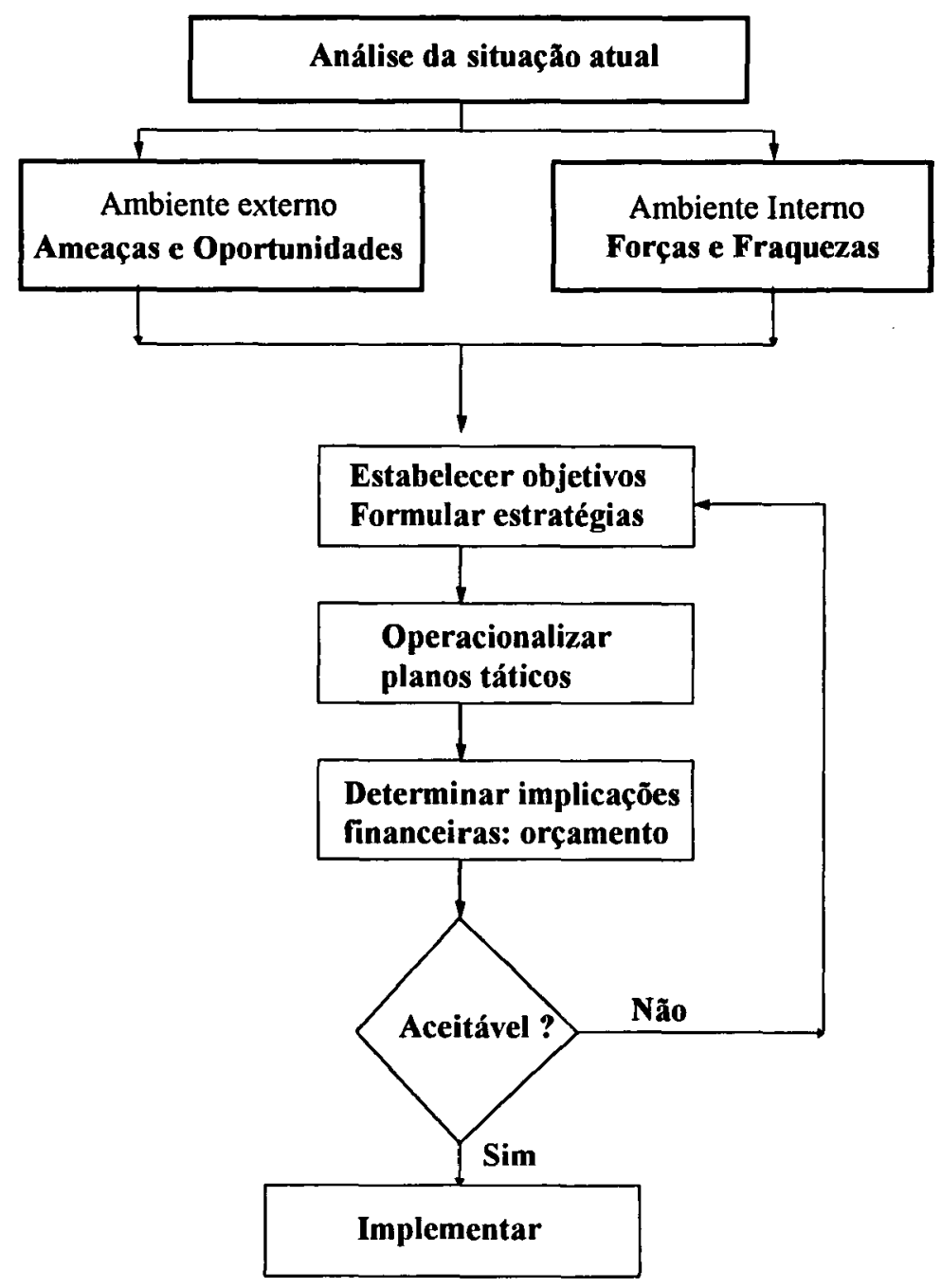




\section{Anexo}

\section{Figura 2}

\section{Relação de Diferenciais na Oferta Imobiliária}

\begin{tabular}{|c|c|c|c|}
\hline$\overline{\text { Adega }}$ & Chapelaria & Famácia los.Soc. & Piscinas: \\
\hline Alarme & Churrasqueira: & Floreiras & c/Deck \\
\hline Alarme c/Sensores & c/Quiosque & Fonte de Água & c/Pérgula \\
\hline A larme Inc./Roubo & c/Sala de Apoio & Forno $\mathrm{p} / \mathrm{Pizza}$ & Térm ica \\
\hline A larme Individual & Circ.Interno de TV & Freezer & Pisos em Ip ê \\
\hline Aloj.p/Motorista & Closet & Gabinete & Pista de Cooper \\
\hline Andar Giratório & Coffee-Shop & Galeria p/Obras de & Pista Patinação \\
\hline Anfiteatro & Cofre & Arte & Planta Flexivel \\
\hline Ant.Coletiva T V & Comp.p/Louças & Garagens: & Play Ground \\
\hline Ant.Parabólica & Cond.Informatiz. & c/Depós.Individual & Play Gr.Pedagóg. \\
\hline Apto.Mobiliado & Controle llum in. & $p / B \operatorname{arcos}$ & Plenário \\
\hline Ap.Parcialm.Mob. & Contr.Rede Elétr. & Guarita a Prova & Porta Entr.G irat. \\
\hline Aquecim.Central & Copa/Coz.Conjug. & de Balas & Portão Automát. \\
\hline Aguecim.Solar & Cozinh.Americana & Gás Central & Portas Maciças \\
\hline ArCond.Central & Cozinha c/Fogão & Gerador & c/Des.Personaliz. \\
\hline Arc/TermoAcum. & Coz.c/Frigobar & Grades & Pub \\
\hline Armário Embutido & Criado-Mudo & Hall Sociale & Quadrasde: \\
\hline Arm.p/Louças & Deck & De Serviços & Esportes Ilu $\mathrm{m}$ in. \\
\hline Arq.de Interiores & Dep.Empregada & Hidromassagem & Futebolp/Sete \\
\hline Baby-House & Despensa & Home Bank & Paddle \\
\hline Bancadas Granito & Dorm.Reversivel & Hospital p/Plantas & Peteca \\
\hline Banh.Hidromassag & Elevadores com: & Hotel na Mudanca & Squash \\
\hline$\overline{B a r}$ & Ascens.Eletrónico & Interfone & Tênis \\
\hline Berçário & Contr.Acesso Pav. & Jardim de Inverno & Poliesportivas \\
\hline Biblioteca & Tráf.p/Computad. & Jardim com & Quarto Reversivel \\
\hline Bicicletário & Elev.Panorâmico & Tratam.Pa is a gist. & em B iblioteca \\
\hline Mesas de Bilhar & p/Lavagem Autos & Lareira & em Salade TV \\
\hline Box c/V.Blindex & Privativo(cód.ac.) & Lava-Jatop/Autos & Recepção \\
\hline Boxp/Lav.Carros & c/Zoneamento & Lavabo & Redep/Comput. \\
\hline Cabine Telefôn $\mathrm{nica}$ & Esc.Pressurizadas & Lavanderia & Restaurante \\
\hline Canil & Escritório: & Lav.Self Service & Rouparia \\
\hline Castelinho Infantil & Reversivel Dorm. & Local.Privileg iada & Roup.p/Cobertore \\
\hline Centrais de: & c/Piso Elevado & Máquina de Gelo & Sacadas com: \\
\hline Compras & Espera Ar Janela & Mármores Import. & Churrasqueira \\
\hline Congelados & Estacionamentos: & Monitorac.Video & Rebaixam.Mógno \\
\hline$\overline{\mathrm{Fax}}$ & p/Jet Sky & Mudanca: & Salas de: \\
\hline Centrais de: & $p / V$ isitantes & Pgto.dos Custos & Convenções \\
\hline Portaria & Estufa & No.de Quartos & c/Retroprojetor \\
\hline Recados & Estufa p/Plantas & No.de Suites & de estudos \\
\hline Segurança & Exaustor Eólico & Orient.p/Nascente & de Lobby \\
\hline Servicos & Fachada c/Granito: & Paredes Flexiveis & de Musculação \\
\hline Telefonia & Fixadop/Grampos & Par.Removiveis & de TVeSom \\
\hline
\end{tabular}




\section{Anexo C}

\section{Figura 3}

\section{Estratégias de Segmentação e Atuação em Nichos}

\begin{tabular}{|c|c|c|}
\hline Área/Nicho de Atuaçāo & Incorporador & Características \\
\hline Imóveis pequenos & Zenatti (Florianópolis) & $\begin{array}{l}\text { Projetos com sala e cozinha em } \\
\text { ambiente integrado }\end{array}$ \\
\hline Residências com serviços & Inpar (São Paulo) & $\begin{array}{l}\text { Apartamentos destinados a } \\
\text { solteiros, divorciados, casais sem } \\
\text { filhos }\end{array}$ \\
\hline Residências para idosos & $\begin{array}{l}\text { Langford \& Male (1991) - } \\
\text { Citaçāo }\end{array}$ & $\begin{array}{l}\text { Projetos direcionados às } \\
\text { necessidades dos idosos }\end{array}$ \\
\hline Flats & Parthenon (Curitiba) & $\begin{array}{l}\text { Operação de flats (aptos. com } \\
\text { característica de hotel) }\end{array}$ \\
\hline Galpões industriais & Zaidan (São Paulo) & $\begin{array}{l}\text { Pequenos investimentos em } \\
\text { terrenos de periferia }\end{array}$ \\
\hline Condomínios industriais & São Gabriel (São Paulo) & $\begin{array}{l}\text { Vias internas e serviços } \\
\text { compartilhados }\end{array}$ \\
\hline Cemitérios Verticais & Bratke (São Paulo) & $\begin{array}{l}\text { Viabilização em terrenos } \\
\text { urbanos menores }\end{array}$ \\
\hline Fábricas de alimentos e bebidas & Plaenge (Londrina) & Projetos e instalações industriais \\
\hline $\begin{array}{l}\text { Escritórios para profissionais } \\
\text { liberais }\end{array}$ & Sulimob (São Paulo) & $\begin{array}{l}\text { Salas flexíveis, em média com } 30 \\
\mathrm{~m}^{2}\end{array}$ \\
\hline Mansões & Aronis (São Paulo) & $\begin{array}{l}\text { Palacetes c/área acima de } 500 \mathrm{~m}^{2} \\
\text { e garagens p } / 6 \text { carros }\end{array}$ \\
\hline Shoping Centers & Maiojama (Porto Alegre) & Parcerias com Fundos de Pensão \\
\hline
\end{tabular}

Fonte: Gazeta Mercantil 